\title{
Monitoring Gaseous and Particulate Air Pollutants near Major Highways in Abeokuta, Nigeria
}

\author{
*11OLAYINKA, OO; ADEDEJI, OH; AJIBOLA, FO \\ Department of Environmental Management and Toxicology, Federal University of Agriculture, PMB \\ 2240, Abeokuta, Ogun State, Nigeria
}

\begin{abstract}
High traffic volume and traffic congestion on Nigerian roads have led to increase in the concentration of pollutants in the air $t$ posing health risks for human population. This study investigates air quality due to vehicular emissions in some busy roads in Abeokuta metropolis, Nigeria. Air pollutants such as $\mathrm{CO}, \mathrm{CO}_{2}, \mathrm{NO}, \mathrm{NO}_{2}, \mathrm{SO}_{2}, \mathrm{H}_{2} \mathrm{~S}$ ) and suspended particulate matter (SPM) were determined using an active sampler for both dry and wet seasons. The results shows concentration of $\mathrm{CO}$ in the urban air ranging from $1.58-8.50$ ppm during the dry season and $1.22-25.75$ ppm for wet season, while $\mathrm{CO}_{2}$ ranges from $11800-26900 \mathrm{ppm}$ for dry season and $9200-26700 \mathrm{ppm}$ in wet season. NO ranged from $0.04-2.60 \mathrm{ppm}$ for dry season and $0.02-0.66 \mathrm{ppm}$ for wet season while $\mathrm{NO}_{2}$ ranged from $0.09-3.40 \mathrm{ppm}$ in dry season and $0.04-1.12 \mathrm{ppm}$ in the wet season. $\mathrm{SO}_{2}$ ranged between $0.06-2.18 \mathrm{ppm}$ in dry season compared to $0.05-0.82 \mathrm{ppm}$ in wet season. SPM varies between $51.00-642.25 \mathrm{ppm}$ in dry season and 29.50 - $170.75 \mathrm{ppm}$ in wet season. High concentrations of $\mathrm{CO}_{2}, \mathrm{NO}, \mathrm{NO}_{2}, \mathrm{SO} 2, \mathrm{H}_{2} \mathrm{~S}$ and SPM were obtained during the dry season compared to the wet season and can be attributed to vehicular emissions due high traffic volume on the roads. The concentrations of pollutants examined were above the World Health Organization (WHO) limits at all the sites. C JASEM
\end{abstract}

http://dx.doi.org/10.4314/jasem.v19i4.23

KEYWORDS: Gaseous Pollutants, Air Quality, Abeokuta Metropolis, Transportation, healths

\section{INTRODUCTION}

Road vehicles are one of the principal emitters of gaseous and particulate air pollutants and are major contributors to urban air pollution (Chen, et al., 2009; $\mathrm{Li}, 2011$ ). Air pollution from traffic poses a serious health threat to inhabitants living or working near busy roads (Fu, 2001; Brechler and Fuka, 2013).

Road vehicles accounted for 22.5 and $21.2 \%$ of total global nitrogen oxides (NOx) and particulate matter (PM) emissions respectively in 2000 (Borken, et al., 2007; Takeshita, 2012). Vehicular pollution is caused due to tail-pipe exhaust emission depending on changes in driving condition, engine condition, and fuel composition in air/fuel ratio. Nearly $50 \%$ of global $\mathrm{CO}$, hydrocarbon, and NOx emissions from fossil fuel combustion come from gasoline- and diesel-powered engines (Ayub and Baig, 2013). The combustion of gasoline and other hydrocarbon fuels in automobiles, trucks and jets airplanes produce several primary pollutants like nitrogen oxides, sulphur dioxides and carbon monoxide (Goyal, 2006; Osuntogun and Koku, 2007; Taiwo et al., 2014). Poor economic condition of developing countries like Nigeria coupled with poor vehicle maintenance culture and importation of used vehicles have in many ways greatly contributed to the rise in the figure of emission concentration (Ibrahim, 2009). In addition, traffic-related pollution has also increased due to low quality fuel, poor traffic regulation and lack of air quality implementation (Salimol and Jacko, 2007; Okunola, et al., 2012). Air pollutants are increasing rapidly in many urban areas of the developing world such as Nigeria where environmental regulations are relatively lax or nonexistent (European Commission, 2001; Olajire et al., 2011; WHO, 2002).

Emission of gaseous and particulate air pollutants close to people's breathing zone pose a great risk on human health (WHO, 2002). (Abdollahi et al. (1998) reported that an increase of $6 \mathrm{ppm}$ in ambient concentration of $\mathrm{CO}$ with $1 \%$ elevation of blood carboxy-haemoglobin in some occupational bus drivers in Tehran, Iran. Short-term exposures to $\mathrm{NO}_{2}$ gas may cause airway responsiveness and lung function injury and long-term exposures may reduce immunity and lead to respiratory infections (Han and Naeher, 2006). Abeokuta the study area is experiencing increase growth in both human population and vehicular traffic, which has led to increasing cases of air pollution. This study assesses the levels of gaseous and particulate pollutants along high traffic roads in metropolis. and the health impact of vehicular emissions on people working or living at the selected sites was evaluated by administration of questionnaires.

\section{MATERIALS AND METHOD}

Study Location: Abeokuta is the largest city and capital of Ogun State, South-West, Nigeria. It is situated on the east bank of the Ogun River, near a group of rocky outcrops in a wooded savanna; 48 
miles north of Lagos by railway, or 81 miles by water. The study area is located between (latitude $7^{\circ}$ $9^{\prime}$ and $7^{\circ} 14^{\prime}$ north) and (longitude $3^{\circ} 26^{\prime}$ and $3^{\circ} 40^{\prime}$ east). The town is within the rainforest zone of Nigeria, its geographical location making it easily accessible to Lagos, the commercial capital of Nigeria, industrial state and main seaport. The city has two seasons; the wet season between April and October and the dry season between November and March. Abeokuta metropolis has expanded in all directions and the growth is unprecedented for an increase of 40 square kilometres in period of just three years (1981-84). The built up area of Abeokuta had increased from 136 square kilometres to 176 square kilometres (Ogun State URPB, 2011) within this period. The construction of inter-city roads linking Abeokuta to Lagos to the south, Ibadan to the North West, Benin Republic to the West and Sagamu to the south have created and attracted rapid development along these traffic corridors.

Roads in Abeokuta metropolis are some of the most congested in Nigeria due to rapid urban expansion and population growth. Traffic demand in Abeokuta metropolis now surpasses the road capacity growth and high usage has resulted in roadways that are in constant need of repair. Major roads in Abeokuta metropolis were considered due to high traffic volume always experienced on these roads and the location of commercial activities along the roads. Five sampling sites were selected which include; Iyana Mortuary, Sapon, Lafenwa, Kutoand Panseke. In addition, Ibara Government Residential Area along M.K.O. Abiola Stadium was selected as control site. Figure 1 shows Abeokuta Metropolis and Sampling Sites.

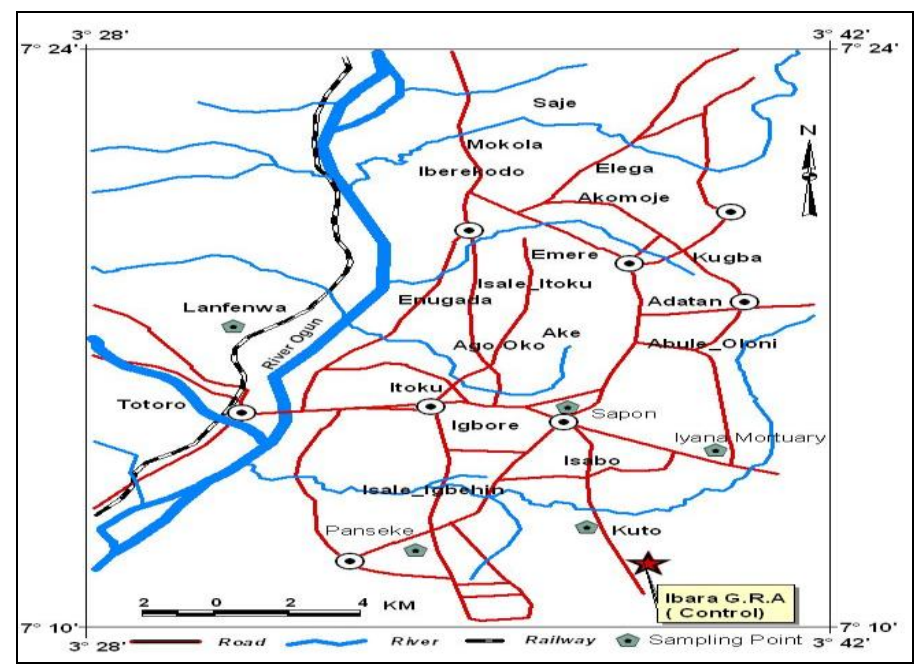

Fig 1: Map showing the sampling locations in Abeokuta Metropolis, Nigeria

Sampling and Analysis: This study was conducted across two different seasons (dry and wet seasons). Specifically, sampling and analysis for gaseous pollutants were carried out in February 2014and May 2014 covering both dry and wet seasons respectively. The air pollution measurements were carried out using direct reading, automatic in situ gas monitors. Air pollutant such as Carbon monoxide (CO), Carbon dioxide (CO2), Nitrous oxide (NO), Nitrogen dioxide (NO2), Sulphur dioxide (SO2), Hydrogen Sulphide (H2S) and Suspended Particulate Matter (SPM) were determined using a Land Duo Multi Gas Monitor
(PDR1200). Each measurement was allowed to wait for 5 minutes before reading in order to ensure that stable reading was recorded. The measurement was carried out in triplicate. The traffic volume was determined by directly observing and counting the traffic during the usual peak period of 8 to 11 amand 2 to $6 \mathrm{pm}$. for two consecutive days in each sampling in triplicate. The average number of traffic at each site per hour was calculated. The average traffic volume is shown in Table1.

Table 1: Traffic volume of the sampling sites

\begin{tabular}{|c|c|c|c|}
\hline \multirow[t]{2}{*}{ Sampling Site } & Coordinates & \multicolumn{2}{|c|}{ Average Traffic Volume per hour } \\
\hline & N07.15, E003.36 & $\begin{array}{c}\text { Dry Season } \\
5658\end{array}$ & $\begin{array}{c}\text { Wet Season } \\
5635\end{array}$ \\
\hline Kuto & N07.14, E003.35 & 4321 & 4224 \\
\hline $\begin{array}{l}\text { Panseke } \\
\text { Lafenwa }\end{array}$ & $\begin{array}{l}\text { N07.13, E003.33 } \\
\text { N07.16, E003.33 }\end{array}$ & $\begin{array}{l}6900 \\
3150\end{array}$ & $\begin{array}{l}6875 \\
3115\end{array}$ \\
\hline $\begin{array}{l}\text { Sapon } \\
\text { Control } \\
\text { GRA) }\end{array}$ & $\begin{array}{l}\text { N07.16, E003.35 } \\
\text { N07.13, E003.35 }\end{array}$ & $\begin{array}{c}2808 \\
150\end{array}$ & $\begin{array}{l}2050 \\
120\end{array}$ \\
\hline
\end{tabular}


Simultaneously, the level of air pollutants at each of the sampling sites was determined during the peak periods for two consecutive days in each sampling. The pollution impact of the air pollutants on health of residents and workers around the sampling sites was evaluated through administration of questionnaires. Questionnaire was administered randomly at each of the sampling sites to men and women with age 15 and above with a particular emphasis on the age range between 15 and 50. Responses from the interviews

\section{RESULTS AND DISCUSSION}

The results of gaseous and particulate pollutants were stated as $\mathrm{CO}$ ranged from $1.58-8.50 \mathrm{ppm}$ during the dry season and $1.22-25.75 \mathrm{ppm}$ during the wet season; $\mathrm{CO}_{2}, 11800$ - 26900 ppm (dry season) and 9200 - 26700 ppm (wet season); NO, $0.04-2.60$ ppm (dry season) and $0.02-0.66$ ppm (wet season); $\mathrm{NO}_{2}, 0.09-3.40$ ppm (dry season) and $0.04-1.12$ were used to gather information about the personal data of respondents and their experiences concerning the possible impacts of these air pollutants on their health.

Statistical Analysis: Data collected on air pollutants levels were analysed for descriptive statistics (mean), and Pearson's correlation using the Excel Windows Microsoft office

ppm (wet season); $\mathrm{SO}_{2}, 0.06-2.18$ ppm (dry season) and $0.05-0.82 \mathrm{ppm}$ (wet season); $\mathrm{H}_{2} \mathrm{~S}, 0.03-1.74$ ppm (dry season) and $0.03-0.48 \mathrm{ppm}$ (wet season); SPM, 51.00 - 642.25 ppm (dry season) and 29.50 $170.75 \mathrm{ppm}$ (wet season). Highest concentrations for $\mathrm{CO}_{2}, \mathrm{NO}, \mathrm{NO}_{2}, \mathrm{SO}_{2}, \mathrm{H}_{2} \mathrm{~S}$ and $\mathrm{SPM}$ were recorded during the dry season and $\mathrm{CO}$ during the wet season (Tables 2-3)

Table 2:Mean Concentration of Gaseous and Particulate Pollutants in Dry Season (ppm)

\begin{tabular}{lccccccc}
\hline LOCATION & $\mathbf{C O}$ & $\mathbf{C O}_{2}$ & $\mathbf{N O}$ & $\mathbf{N O}_{2}$ & $\mathbf{S O}_{2}$ & $\mathbf{H}_{2} \mathbf{S}$ & $\mathbf{S P M}$ \\
\hline Iyana Mortuary & 6.86 & 26900 & 2.60 & 3.40 & 2.00 & 1.19 & 525.00 \\
Kuto & & & & & & & \\
Panseke & 8.50 & 26700 & 2.28 & 2.86 & 2.18 & 1.09 & 336.50 \\
Lafenwa & 4.75 & 26800 & 1.41 & 2.04 & 1.34 & 1.01 & 245.25 \\
Sapon & 5.69 & 25800 & 1.79 & 2.61 & 1.51 & 1.74 & 268.75 \\
Control & 4.26 & 24600 & 1.35 & 2.21 & 1.71 & 0.98 & 642.25 \\
(Ibara G.R.A.) & 1.58 & 11800 & 0.04 & 0.09 & 0.06 & 0.03 & 51.00 \\
& & & & & & & \\
\hline
\end{tabular}

Table 3:Mean Concentration of Gaseous and Particulate Pollutants in Wet Season (ppm).

\begin{tabular}{lccccccc}
\hline LOCATION & $\mathbf{C O}$ & $\mathbf{C O}_{2}$ & $\mathbf{N O}$ & $\mathbf{N O}_{2}$ & $\mathbf{S O}_{2}$ & $\mathbf{H}_{2} \mathbf{S}$ & $\mathbf{S P M}$ \\
\hline Iyana Mortuary & 19.75 & 26700 & 0.66 & 1.12 & 0.64 & 0.33 & 142.50 \\
Kuto & 13.50 & 22100 & 0.37 & 0.80 & 0.80 & 0.46 & 140.25 \\
Panseke & 25.75 & 23800 & 0.59 & 0.88 & 0.77 & 0.45 & 170.75 \\
Lafenwa & 5.25 & 23700 & 0.28 & 0.49 & 0.73 & 0.48 & 102.50 \\
Sapon & 3.39 & 21600 & 0.44 & 0.72 & 0.55 & 0.31 & 82.75 \\
$\begin{array}{l}\text { Control } \\
\text { (Ibara G.R.A.) }\end{array}$ & 1.22 & 9200 & 0.02 & 0.04 & 0.05 & 0.03 & 29.50 \\
\hline
\end{tabular}

High concentrations of $\mathrm{CO}$ were found in wet season at Iyana Mortuary, Kuto and Panseke which could be due to slow traffic movement observed at these sites, while high concentrations were observed in the dry season at Lafenwa and Sapon. The highest concentration of $\mathrm{CO}$ was found at Panseke (Figure 2). Seasonal variations of $\mathrm{CO}, \mathrm{CO}_{2}, \mathrm{NO}, \mathrm{NO}_{2}, \mathrm{SO}_{2}, \mathrm{H}_{2} \mathrm{~S}$ and SPM concentrations across the sites are illustrated in Figures 2.

High concentrations of $\mathrm{CO}$ were found in wet season at Iyana Mortuary, Kuto and Panseke which could be due to slow traffic movement observed at these sites, while high concentrations were observed in the dry season at Lafenwa and Sapon. The highest concentration of $\mathrm{CO}$ was found at Panseke (Figure 2). Seasonal variations of $\mathrm{CO}, \mathrm{CO}_{2}, \mathrm{NO}, \mathrm{NO}_{2}, \mathrm{SO}_{2}, \mathrm{H}_{2} \mathrm{~S}$ and SPM concentrations across the sites are illustrated in Figures 2.

The concentrations of $\mathrm{CO}$ at all the sites could be attributed to emissions from motor vehicles associated with high traffic density and congestion as substantiated by the correlation coefficient, $r^{2}=0.60$, $\mathrm{p}<0.05$ (Table 4) between the traffic volume and the concentration of CO. This findings agreed with Han and Naeher (2006), where a high concentration of $\mathrm{CO}$ was attributed to high traffic intensity and congestion 

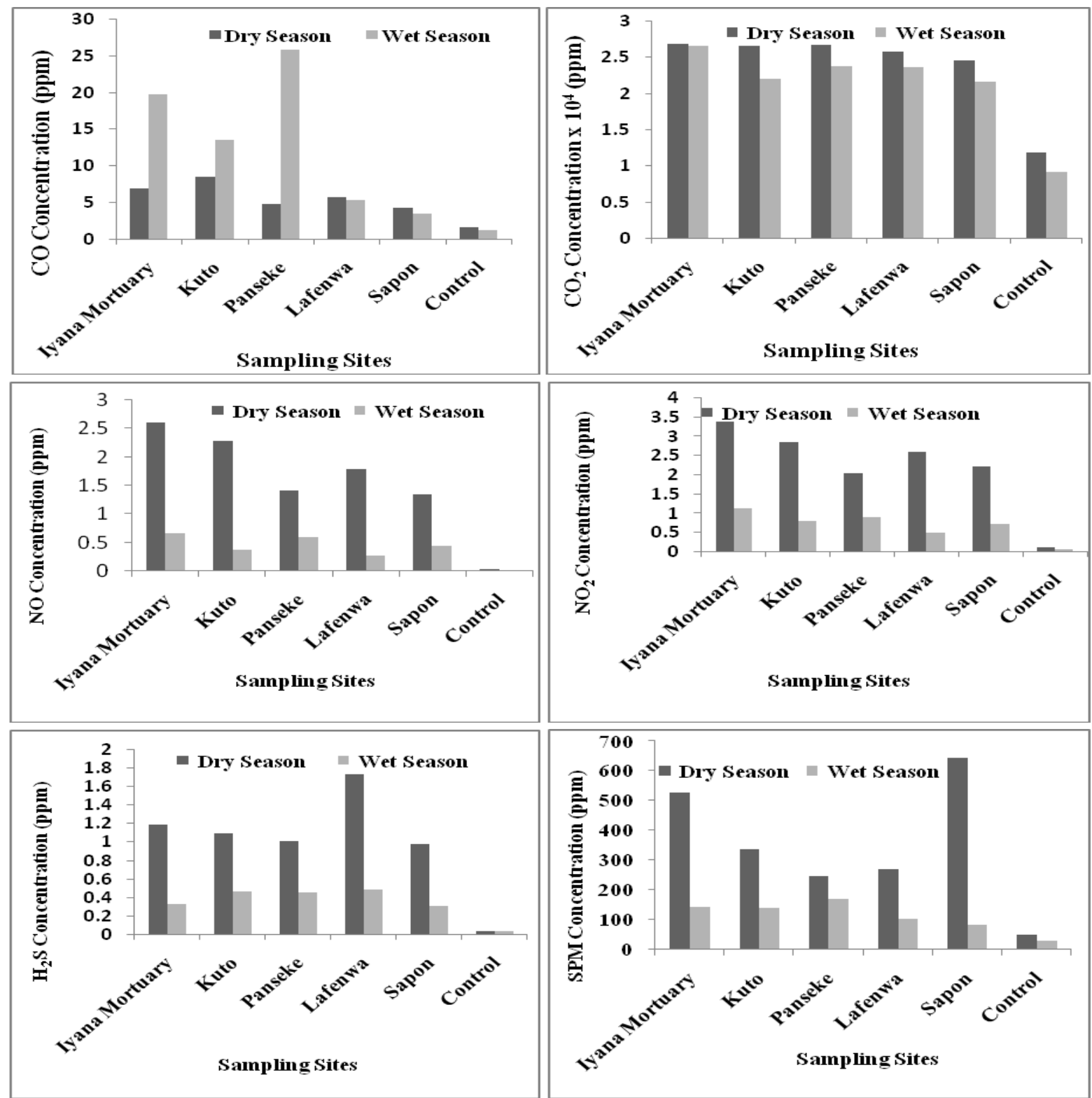

Fig 2: Seasonal Variation of selected pollutants across the sampling sites

Table 4: Correlation Coefficients between Pollutants and Traffic Volume.

\begin{tabular}{ll}
\hline POLLUTANTS & $\begin{array}{l}\text { TRAFFIC } \\
\text { VOLUME }\end{array}$ \\
\hline CO & 0.60 \\
CO2 & 0.84 \\
NO & 0.63 \\
NO2 & 0.70 \\
SO2 & 0.65 \\
H2S & 0.53 \\
SPM & 0.34 \\
\hline
\end{tabular}

Congestion along major roadways in the metropolis has significant effect in traffic and the atmospheric environment conditions. The poor traffic situation in Abeokuta metropolis arises because of the various land-use activities including administrative, commercial, educational, patterns and circulation/ tranportation land use. Futhermore, inadequate parking spaces, erratic public transport, over-reliance on road and indiscipline among the motorists are other factors responsible for traffic congestion in the city like any other Nigeria cities (Ogunsanya, 2002; Vandu-Chikolo et al.,2004). The mean concentrations of $\mathrm{CO}$ at all the sites were within the USEPA (2008) limits of $9 \mathrm{mg} / \mathrm{m}^{3}(8.50 \mathrm{ppm})$ during dry season but the concentrations were above the USEPA limits of 9 $\mathrm{mg} / \mathrm{m}^{3}$ (13.50-25.73 ppm) during the wet season at Iyana Mortuary, Kuto and Panseke, except at Lafenwa and Sapon (Table 3). The ambient CO along 
the roads, when compared with values reported in literature, was found to be lower than the range of 232 - 317 ppm reported in three cities of Nigeria(Lagos, Ibadan, Ado Ekiti), Osuntogun and Koku, (2007) and also falls within the value of $1.79-$ 51.38 ppm reported in Ogbomoso (Ojo and Awokola, 2012). The values reported in this study agreed with the values of $4.25-8.93 \mathrm{ppm}$ and $8.70-13.00 \mathrm{ppm}$ found in Kano and Port Harcourt, Nigeria, respectively (Okunola et al., 2012 ; Augustine 2012). Carbon Monoxide is produced as a result of incombustion of hydrocarbon fuels. It is highly toxic even at small levels of concentration and has been known to decrease human efficiency (Ojo and Awokola, 2012). Due to the high concentrations of $\mathrm{CO}$ obtained in this study, the people living or working around the study areas are exposed to health threats from $\mathrm{CO}$ pollution. $\mathrm{CO}$ is capable of increasing the blood carboxy-haemoglobin (Abdollahi et al., 1998).

High concentrations of $\mathrm{CO}_{2}$ were detected at all the sites during both dry and wet seasons, with the highest concentration of $26900 \mathrm{ppm}$ at Iyana Mortuary. However, the concentrations of $\mathrm{CO}_{2}$ were a bit lower during wet season than in the dry season as shown in Figure $3 . \mathrm{CO}_{2}$ may arise from the combustion of coal for domestic cooking at various points along the roads of the study areas. However, from the results obtained by performing correlation regression analysis, $\mathrm{CO}_{2}$ was strongly correlated with traffic volume $\left(\mathrm{r}^{2}=0.84, \mathrm{p}<0.01\right)$. This invariably suggests that most of the $\mathrm{CO}_{2}$ are emitted from vehicular activities. The mean concentration of $\mathrm{CO}_{2}$ in both seasons; 11800 - 26900 ppm (dry season) and 9200 - 26700 ppm (wet season) was above the recommended WHO (2005) thresh hold limit value (TLV) of $500 \mathrm{ppm}$ indicating that $\mathrm{CO}_{2}$ pollution was very serious along the traffic lines in Abeokuta Metropolis.

NO was found to be high at all sites during the dry season with the highest concentration of $2.60 \mathrm{ppm}$ at Iyana Mortuary as shown in Figure 4 . This is possibly due to emissions from fossil fuel combustion in vehicles as substantiated by the correlation coefficient, $r^{2}=0.63(p<0.05)$ between the traffic volume and the concentration of NO. Nearly $50 \%$ of NOx emissions from fossil fuel combustion come from gasoline- and diesel-powered engines (Ayub and Baig, 2013). Nitrogen oxides ( $\mathrm{NO}$ and $\mathrm{NO}_{2}$ ) are the most important of the many air pollution agents that are emitted into the atmosphere (Brechler and Fuka, 2014). From the results, high levels of $\mathrm{NO}_{2}$ were obtained at all sites during the dry season with the highest concentration of $3.40 \mathrm{ppm}$ at Iyana Mortuary as illustrated in Figure 5. This could be attributed to emissions from increasing number of vehicles such as diesel engines of trucks, taxis, cars and motorcycles as well as on-going road expansion activities at the site. In accordance with Kimmel and Kaasik (2003), the high levels of $\mathrm{NO}_{2}$ may be due to increase in the number of vehicles, poor maintenance of these vehicles and narrow roads in the city of Abeokuta. A correlation coefficient, $\mathrm{r}^{2}=0.70(\mathrm{p}<$ 0.01 ) between the concentration of $\mathrm{NO}_{2}$ and traffic volume further suggest that the concentrations of $\mathrm{NO}_{2}$ were from vehicular emissions. The mean concentrations of $\mathrm{NO}_{2}$ at all sites was above the WHO (2006) guideline for ambient air quality of $(0.1 \mathrm{ppm}) 200 \mu \mathrm{g} / \mathrm{m}^{3}$. In comparison of the levels of $\mathrm{NO}_{2}$ from the study areas with values reported in literature, $\mathrm{NO}_{2}$ levels were higher than the values of 0.6 - $1.5 \mathrm{ppm}$ reported in Lagos, Ibadan and Ado Ekiti (Osuntogun and Koku, 2007) as well as those reported by Okunola et al., $2012(0.11-0.43 \mathrm{ppm})$ in Kano and,Ojo and Awokola, 2012 (0.013 - 0.039 ppm) in Ogbomoso.

$\mathrm{NO}_{2}$ is highly toxic and corrosive. It is irritating to the eyes and respiratory tract (Osuntogun and Koku, 2007). Studies have reported positive correlations between seasonal variations in hospitalization and traffic -related air pollutants such as nitrogen oxides, carbon monoxide and fine fraction particles (Chen $e t$ al.,2006; Migliaretti et al., 2005). High levels of $\mathrm{NO}_{2}$ gas exposure can give cough, shortness of breath as well as increase in the chances of respiratory infections (Han and Naeher, 2006).

$\mathrm{SO}_{2}$ concentrations were high at all sites during the dry season with the highest concentration of 2.18 ppm at Kuto as shown in Figure 6. This could be due to emissions from vehicles and generating sets. The mean concentration of $\mathrm{SO}_{2}$ at all sites was above the WHO (2006) guidelines for ambient air quality which stipulates $0.2 \mathrm{ppm}\left(500 \mu \mathrm{g} / \mathrm{m}^{3}\right)$ for 10 minutes average time. The concentrations of $\mathrm{SO}_{2}$ obtained in this study falls within the value of $0.8-2.9 \mathrm{ppm}$ obtained by Osuntogun and Koku (2007) at Lagos, Ibadan and Ado Ekiti. The values reported in this study was higher than those reported by Ojo and Awokola (2012), Okunola et al. (2012), and Augustine (2012).

Several studies have established air pollution as a significant factor associated with increased morbidity in asthmatics (Hansen et al., 2008). The health effect of $\mathrm{SO}_{2}$, include aggravation of illness in those with already weakened respiratory function such as asthmatics (Augustine, 2012). Therefore, people working or living around the study areas are exposed to respiratory dysfunctions. In Europe, increased exposure to traffic related air pollutants has been ascribed as one speculative reason for rise in allergic disease (Krzyzanowski et al., 2005; Morgenstern et al.,2008).

Pollution indices such as ratios of levels of some gaseous pollutants can further confirm traffic 
emissions as a source of pollution. High $\mathrm{CO} / \mathrm{NO}_{\mathrm{X}}$ and low $\mathrm{SO}_{2} / \mathrm{NO}_{\mathrm{X}}$ indicate mobile emission source while low $\mathrm{CO} / \mathrm{NO}_{\mathrm{X}}$ and high $\mathrm{SO}_{2} / \mathrm{NO}_{\mathrm{X}}$ indicates stationary emission source (Aneja et al., 2001). The results obtained in this study showed high $\mathrm{CO} / \mathrm{NO}_{\mathrm{X}}$ and low $\mathrm{SO}_{2} / \mathrm{NO}_{\mathrm{X}}$ thereby supporting vehicular emission of the gaseous pollutants. Futhermore, $\mathrm{H}_{2} \mathrm{~S}$ levels were found to be high at all sites during the dry season, with the highest concentration of $1.74 \mathrm{ppm}$ at Lafenwa as shown in Figure 7. This could be attributed partly to the decay of foodstuff, waste and refuse generated from a major market within these sites and left along the road. $\mathrm{H}_{2} \mathrm{~S}$ is a gas emitted during the decay of organic matter. From the results obtained in Pearson correlation regression analysis $\left(\mathrm{r}^{2}\right.$ $=0.53, \mathrm{p}<0.05)$, vehicular emission source of $\mathrm{H}_{2} \mathrm{~S}$ cannot be ruled out. The mean concentrations of $\mathrm{H}_{2} \mathrm{~S}$ at all sites was above the Federal Environmental Protection Agency (FEPA,1991) limits of $0.02 \mathrm{ppm}$. The $\mathrm{H}_{2} \mathrm{~S}$ level in this study was lower than the value observed in Kano, Nigeria (Okunola et al, 2012 ). The concentration of SPM at all studied sites was high during the dry season, with the highest concentration of $642.25 \mathrm{ppm}$ at Sapon as illustrated in Fig 8. This high value could be attributed to resuspension of dust during construction activities such as demolition of buildings for road expansion and bridge construction in the area, as well as emissions from vehicular exhaust.

Responses from interviews conducted by administering questionnaires indicated that respondents which comprise the people living and working around the sampling sites (food vendors, trades, road cleaners, motor cycle riders, transport union workers, taxi drivers and technicians) suffer from air pollution related diseases such as headache, cough, sneezing, nasal congestion, eye irritation, , throat irritation and fatigue.

Traffic exhaust is one of the main sources of air pollution, especially in urban areas where populations are exposed to the highest air pollution levels (Hansen et al., 2008). High levels of vehicle- related emissions have been linked to high density traffic sites and areas very close to busy roads typically have a high concentration of emissions (Longley et al., 2004; Campbell et al., 2007). Studies have reported that exposure to pollutants is elevated in urban areas with high traffic volumes and heavily travelled highway corridors (Zeka et al., 2005). In Abeokuta metropolis, areas such as Panseke, Ibara, Iyana Mortuary, and Lafenwa contain a high concentration of people, including pedestrians, or people within buildings alongside the road. It is also important to note that individuals at all stages of their life are at risk from traffic pollution, however, the severity of the hazard varies with age and underlying medical conditions (Campbell et al., 2007). Health impacts are greater for people who work close to traffic than for those that are not occupationally exposed. Populations exposed through occupations that lead to extended periods of time on or near roads and highways such as traffic officers, street cleaners and street vendors have higher risk of the impacts of traffic related emissions (Tomao et al., 2002; Tamura et al.,2003; Randem et al., 2004; Dragonieri et al., 2006).. Ruchirawat et al., (2005) reported increased concentrations of vehicle exhaust carcinogens associated with cancer risk like PAHs and VOCs (e.g. benzene and 1,3- butadiene) among street vendors, while Finkelstein et al., (2004) observed that residential proximity to a major road has been associated with a mortality rate advancement period of 2.5 years.

Conclusion: Traffic emissions continue to be a very significant urban health concern, contributing greatly to the overall impact of outdoor air pollution. Concentration of pollutants varies both spatially (by location) and temporally (by time). Traffic volume at Ibara intersection is heavier compared to Lafenwa Intersection due to presence of activities such banks, eatries, shops, market, schools, government monistries and parastatals. Traffic jam is a common occurence around the area during the peak hours in the mornings and evenings and this is compounded by indiscriminate parking along the roads. The results obtained in this study showed lower concentrations in wet season than during dry season for all the pollutants except for $\mathrm{CO}$. The concentrations of $\mathrm{CO}_{2}$ in the study areas was above the WHO (2005) threshold limit value (TLV) of 500 ppm. Similarly the concentrations of $\mathrm{NO}_{2}$ and $\mathrm{SO}_{2}$ were above the WHO limits at all the sites. The concentrations of $\mathrm{CO}$ with few exceptions at some sites was above the USEPA limits. The mean concentrations of $\mathrm{H}_{2} \mathrm{~S}$ at all the sites was above the (FEPA,1991) limits of 0.02 ppm. This study revealed that the concentrations of most gaseous and particulate pollutants in the study areas were due to vehicular emissions. In general, high concentration of air pollutants shows that safety standards are in adequate. This implies that traffic emission within Abeokuta metropolis is not within the safe limits. Hence, the the results revealed that transport-related pollution in Abeokuta metropolis is significant with potentially hazardous health consequences. Traffic congestion undermines the economic productivity and competitiveness, it contributes to air pollution which degrades the quality of life in our metropolitan areas hence adequate measures should be provided by law enforcement agency.

\section{REFERENCES}

Abdollahi, M.,Zadparvar, L.,Ayatollahi, B.,Baradaran, M.,Nikfar, S.,Hastaie, P., 1998.Hazard from carbon monoxide poisoning for bus drivers in Tehran, 
Iran.BullEnvironContamToxicol,61:210-5.

Aneja, V. P., Agarwal, A., Roelle, P. A., Phillips, S. B., Tong, Q., Watkins, N. and Yablinsky, R., 2001. Measurements and Analysis of Criteria Pollutants in New Delhi, India. Environmental International. 27: $35-42$.

Augustine, C., 2012. Impact of air pollution on the environment in Port Harcourt, Nigeria.Journal of Environmental Science and Water Resources. Vol 1(3), $46-51$.

Ayub, S. and Baig, K., 2013.Monitoring the Influence of outdoor vehicular pollutants concentration on indoor air quality of the houses located close to urban roadway/highways, European International Journal of Science and Technology, Vol 2, no 3, 170-180.

Borken, J., Steller, H., Meretei, T. andVanhove, F., 2007. Global and country inventory of road passenger and freight transportation: fuel consumption and emissions of airpollutants in the year 2000. Transport Res Rec 2007, 127-36.

Brechler, J. and Fuka, V. 2014 Impact of noise barriers on air -pollution dispersion. Natural Science, $\quad 6, \quad 377-386$. http://dx.doi.org/10.4236/ns.2014.66038

Campbell, M., Bassil, K., Morgan, C., Lalani, M., Chen, J., Wang, W., Zhang, J., Liu, H., Ren, H., Liu, X., Zhang, W. and Wang, X., 2009. Characteristics of gaseous pollutants near a main traffic line in Beijing and its influencing factors. AtmosphericResearch, 94:470- 480.

European Commission, 2001. Communication from the Commission to the Council, the European Parliament, the Economic and Social Committee and the Committee of the Regions on the sixth environment action programme of the European Community - Environment 2010: our future, our choice. Luxembourg, Office for Offficial Publications of the European Communities (http://europa.eu.int/eurlex/en/com/pdf/2001/en_501PC0031.pdf, accessed26 November 2004).

FEPA, 1991.Guidelines and Standards for Environmental Pollution Control in Nigeria.FederalEnvironmental Protection, Agency Press, Lagos, Nigeria.

Fu, L., 2001."Assessment of vehicle pollution in China", Journal of the Air and Waste Management, Vol. 51 No. 5, 658 - 668 .
Goyal, S., 2006. "Understanding Urban vehicular pollution problem visa-vis ambient air qualities study ofMegairty (Delhi, India), Environmental Monitoring and Assessment, Vol. 119, 557-569.

Han, X., and Naeher, L. P., 2006.A review of trafficrelated air pollution exposure assessment studies in the developing world. Environment International, 32, $106-120$.

Ibrahim, B.G., 2009.“'Strategic approach to reducing vehicle emissions in Nigeria: role of fleet operators",A lecture presented at safety managers training program,FRSC Academy, Nigeria.

Kimmel, V. andKaasik, M., 2003."Assessment of urban air quality in south Estonia bysimple measures.Environ Model Assess8:47-53.

Li, J.,2011.Decoupling urban transport from GHG emissions in Indian cities - a critical review and perspectives. Energy Policy, 39:3503-14.

Ojo, O. O. S., and Awokola, O. S., 2012. Investigation of Air Pollution from Automobiles at Intersections on Some Selected Major Roads in Ogbomoso, South Western, Nigeria. Journal of Mechanical and Civil Engineering (IOSRJMCE), 1:31-35.

Okunola, O. J., Uzairu, A., Gimba, C. E. and Ndukwe, G. I., 2012. "Assessment of Gaseous Pollutants along High Traffic Roads in Kano, Nigeria”, International Journal of Environment and Sustainability, Vol. 1 No. 1, 1-15pp.

Osuntogun, B. A. and Koku, C. A., 2007. Environmental - Impacts of Urban Road Transportation in South - Western States of Nigeria. Journal of Applied Sciences, Vol 7 No 16: $2356-2360$.

Taiwo, A-M, Beddons, D. C-S, Shi, Z. and Hamson, R. M., 2014.Mass and number size distributions of particulate matter components comparison of an industrial site and an urban background site.Science of the Total Environment. 475: 29 38.

Takeshita, T., 2012.Assessing the co-benefits of $\mathrm{CO}_{2}$ mitigation on air pollutants emissions from road vehicle.Applied Energy, 97: 225-237.

USEPA, 2008.National Ambient Air Quality Standards (NAAQS).http://www.epagov/oar/criteria.html accessed 12/02/12 
WHO, 2005.Air Quality Guidelines for Particulate Matter, Ozone, nitrogen dioxide and sulphur dioxide. Globalupdate, 2005.

WHO, 2006. WHO Air quality guidelines: Global update 2005. World Health Organization, Copenhagen, Denmark.

Yang, C. Y., Chen, Y. F., Chuang, H. Y., Cheng, B. H., Sung, F. C. and Wu, T. N., 2002. Respiratory and irritant health effects in tollbooth collectors in Taiwan. Journal of Toxicology and Environmental HealthA, 65:237-243.
Zhou, W., Yuan, D., Ye, S., Qi, P., Fu, C., and Christiani, D. C., 2001. Health effects of occupational exposures to vehicle emissions in Shanghai. International Journal of Occupational and Environmental Health, 7:23-30. 